of prisoners is common, and that at least in one case besides that particularised more prisoners than one have recently been confined in the same apartment.-ED. L.

\section{SUBUNGUAL EXOSTOSES.}

\section{To the Editors of THE LANCET.}

SIRS, -In a letter to THE L $\Lambda$ NCET of Oct. $25 \mathrm{th}$ Dr. Snow says, "Mr. Roger Williams advances the view that these morbid growths are really supernumerary digits." Allow me to state that I never made any such assertion. What I tried to prove was that the germs whence these tumours arise appertain to the rudiment of the lost pre-hallux in its least complete form. Dr. Snow calls my explanation "recondite" and "hardly warrantable." This surprises me; because it is based on the A B C of modern morphology, with which I suppose every pathologist must be acquainted. Even if it were otherwise, the explanation might nevertheless be correct. A striking peculiarity of these tumours is that they develop through cartilage. I am not aware of any scientific evidence in favour of Dr. Snow's contention that periostitis, whether irritative or otherwise, can produce cartilaginous rew formations. Another interesting fact about subungual exostoses is that, unless very completely removed, they commonly grow again. It is stated that after amputation of supernumerary digits the same thing occasionally happens. Here we evidently have to do with grow th and development, qualities not usually regarded as of inflammatory origin, "irritative," or otherwise. $\Lambda \mathrm{s}$ to the inflammatory origin of neoplasms in general, what has been advanced in this sense has, in my opinion, very little weight. It appears to me that the origin of all true neoplasms must eventually be referred to aberrations of the developmental process. In the words of Paget, "It is one and the same power which, being maintained continuously from the germ to the latest period of life, determines all organic formation." I must refer those who care to pursue the subject further to my work on "The Principles of Cancer and Tumour Formation." I am, Sirs, yours truly,

Welbeck-street, W., Oct. 27th, 1890, W. ROGER WILLIAMS.

\section{TREATMENT OF ACROMEGALY.}

\section{To the Editors of THE LANCET.}

SIRS, - From representations of "Goliath" seen in the streets, I formed the opinion some weeks ago that he was suffering from acromegaly, and is I found that the same opinion had been independently arrived at by Mr. E. K. Campbell, I sought and obtained an interview with the giant. He opened the door to me himself, and I at once recognised in him a typical case of the disease in question. I soon, however, discovered that $I$ had been anticipated, and that he had been seen by many medical men on the Continent; amongst others by Professor Virchow, and that he had been shown at one of the societies in London by Dr. Kanthack, who had examined hin with Virchow. Acromegaly is not so rare a disease as is generally thought, and I believe it will turn out to be more common even than myxodema. My brother discovered five cases in an ordinary out-patient department within a few months. One of these I have had the opportunity of treating. I put the patient through a course of arsenic, beginning with five drops three times a day, and increasing the dose two and a half drops every week until half a drachm was reached, when pustular formations began to appear in the skin. He also took from time to time iron, strychnine, and cod-liver oil, and was sent twice to a convalescent home. Although he is by no means cured, yet he is much benefited by the treatment. His head, face, and hands are now considerably reduced in size, and his general health is much improved. In proof of the diminished size of his hands, I rnay mention that the thimble he formerly wore (he is a tailor by trade) and which had to be specially made for him, is now much too large. I remain, Sirs, faithfully yours,

Guilford-street, Oct. 27th, 1890. HARRY CAIIPBELL, M.D.

\section{THE MIDWIVES' REGISTRATION BILL.} To the Editors of THE LANCET.

Sins,-Might I, through your columns, direct the attention of the busy practitioner to the monstrous wrong which he has (for the time) so narrowly escaped. Could he but realise the mischief that might be done by this Bill, not alone to his profession, but to the public, I am satisfied that each unbiased member would put his shoulder to the wheel, and endeavour to avert legislation which is more than retrograde in its character. In trying to gauge this measure two important landmarks must be kept in viewnamely, our duty towards our profession and our duty to the community. Were the former the only consideration we should say better to do away with registration altogether than have such an addendum to our registers. For the sake of analogy let us ask how the clergyman would like every scripture reader and bible woman suddenly elevated to the Clergy List, or how would the lawyer treat an attempt to hoist every clerk and office boy to his level ? Let us be just before being generous. Shall we allow a horde of obstetric Gamps to be tacked to our Register without a murmur? I it not an attempt to raise some thousands of ignorant and pretentious women to a position which their wildest dreams never contemplated? After thirty years' experience of a large mid wifery practice, in the course of which I have frequently come in contact with the class termed "experienced midwives," I must say that, with few exceptions, I found them ignorant of the first principles of the art which they professed. Some of their mistakes must be so patent to obstetricians that to mention them would be superfluous. Is this then the class who are to be registered obstetricians? With regard to the public, instead of allowing them to be further rulled, let them rather be defended from such one-sided legislation; let them see that their newly-registered obstetrician equipped with her certificate would only be a sham, and could not possess a tithe of the knowledge which is expected from her less fortunate (unregistered), althougl more highly educated, sister, the medical and surgical nurse. The action of this Bill would thus present a strange anomaly. Where skilled knowledge and self-reliance are most needed, three months' training will suffice for the midwife, whereas more than as many years are required for the nurse, who, in the hour of trial, is not left to her own resources. Two questions I would ask those members of my profession who have the temerity to support this legislative abortion. One is, What interest have they in its success and the other, Would they place their parturient wife, sister, or daughter in such hands? In conclusion, let me urge upon all the necessity of defending not alone our profession, but also the poor, from misdirected philanthropy. The poor have, in the present day, abundance of qualified medical charities, and well-paid parish officers who cannot refuse them assistance.

I am, Sirs, yours truly,

Liverpool, Oct. 17th, $1890 . \quad$ JAMES M. BENNETT, M.D.

\section{BIRMINGHAM.}

\section{(FROM OUR OWN CORRESPONDENT.)}

\section{Midland Medical Society.}

THE inaugural meeting of this Society will take place on Nov. 12 th, when an address will be delivered by Dr. Mac ewen of Glasgow, the subject being "Aneurysm : its Cure by inducing the Formation of White Thrombi within the Sac" No doubt, from the reputation of the author, this will be an interesting and instructive address. The Society numbers 318 members. During the past year eleven papers were read, fifty-four specimens, cases, \&c., exhibited, and social gatherings after the ordinary meetings continued to find favour. Not unmindful of its flourishing condition, the Society presented three guineas to the Medical Institute, and the same amount to the Medical Benevolent Society.

\section{Hospital Sunday.}

The proceeds this year are below the average. Up to Wednesday the amount collected was f3911 10s. $8 d$ Originating in this town, it is always expected that the traditions of this laudable movement will be sustained, and the occasion is always looked forward to with interest. This year the amount goes to the Queen's Hospital. The Hospital Saturday movement interferes considerably with this annual contribution, and forms a subject of gratifying emulation among the contributors.

\section{City Fever Hospital.}

Some anxiety bas been felt as to the sufficiency of the accommodation in this institution, and it has been con- 